\title{
DEVELOPMENT OF INTEGRATED SCIENCE TEACHING MATERIAL OF OUR DIGESTIVE SYSTEM HEALTH BY INTEGRATING SCIENTIFIC LITERACY FOR GRADE VIII STUDENTS
}

\author{
Asrizal, Mitri Selisne, Festiyed \\ Mathematics and Science Faculty, State University of Padang \\ email:asrizal_unp@yahoo.com
}

\begin{abstract}
In a teaching principle in 21 st century is stated that teaching should has context. This principle emphasizes that teaching should be related to real world context. Integrated science teaching can connected to teaching in the classroom with real world. As the reason is science in the real world is integrated form. Besides that, the implementation of integrated science teaching can improve scientific literacy of students. In real world context the scientific literacy is very important in preparing students in modern life with rapid development of science and technology. Base on this reason, integrated science teaching is required in 2013 curriculum. But integrated science teaching isn't implemented well yet. As an alternative solution of this problem is to develop teaching material of integrated science by integrating scientific literacy of our digestive system health. The general objective of this research is to create the valid teaching material of integrated science on digestive system health in its preliminary product, and practice and effective in its implementation in scientific approach. Type of this research is research and development. Stages of this research consist of understanding the potency and problem, collecting the information, developing the preliminary of product, implementing the teaching material in limited field testing, and revising the teaching material based on result of limited field testing. Design of research in limited field testing is after and before treatment. Instruments to collect the data consist of validity sheet of teaching material, practicality sheet and effectiveness sheet of implementation teaching material of integrated science. Data in this research are analyzed by statistical descriptive analysis, graph method, and correlation compare mean test. Base on the data analysis can be stated two of this research results. First, the teaching material of integrated science by integrating scientific literacy is very valid with average value 88.5. Second, the implementation of teaching material of integrated science by integrating scientific literacy is practice according teacher and students with average value respectively 92,5 and 84.1. On the other hand, the implementation of teaching material of integrated science is effective in scientific approach for students grade VIII in Junior High School.
\end{abstract}

Keywords: Teaching Material, Integrated Science, Digestive System, Scientific Literacy

\section{INTRODUCTION}

Teaching paradigm of the 21 st century emphasizes the ability of students to think critically, to connect science to real world, to understand information communication and technology, and to collaborate with other people. Teaching should be conducted to develop these abilities. At least there are four principles that need to be applied in the 21 st century learning. The fourth principle are development of teaching should be use a student centered teaching, teaching should be a collaborative, teaching should be has relevant context, and schools should be integrated with society (Nichols, 2015). In an effort to prepare students to become responsible citizens, schools should be able to 
facilitate students to engage in a social environment. On this basis, the teaching which is implemented in schools should be based on of this paradigm.

In education, teaching should be conducted be able to develop students literacy because this literacy is important for students to solve various activities in the teaching process and in the daily life activities. Literacy will help students in performing their functions in teaching and in life. Literacy is the ability to read, view, write, design, speak and listen in a way that allows us to communicate effectively and to make sense of the world. On the other word, literacy refers to a basic competency in a given area. For example, reading literacy is the ability to read at a functional level (Ronis, 2001). This ability can be implemented to solve problems in teaching and in real life. Literacy is one of the most important academic skill areas because it influences skill acquisition in other academic areas (Carroll, 2013). By implementing the good literacy, a student is able to develop his potential in himself.

In science teaching, scientific literacy is an important area to help students in responding and making decisions related to science problem in their life. This is mean that scientific literacy is important because an understanding of science provides personal fulfillment and excitement (Robinson, 2001). Heller stated four reasons that scientific literacy is important in life. First, competitiveness and employability are inextricably related to the capacity of individuals to participate actively and promote innovation. Second, in the 21 st century, science and technology have come to play an increasing importantly role in many areas of society. Third, many of the greatest social problems of our time involve important scientific and technological components. Finally, the world is in need of citizens with critical thinking skills (Ogunkola, 2014).

Scientific literacy has several different meaning. Mayer defines scientific literacy as the knowledge of the substantive content of science that is related specifically to understanding the interrelationships among people and how their activities influence the world around them (Akgul, 2004). Scientific literacy is the knowledge and understanding of scientific concepts and processes required for personal decision making, participation in civic and cultural affairs, and economic productivity (Kiyici, 2007). Scientific literacy consists of the knowledge and understanding of scientific concepts and processes required for personal decision making, participation in civic and cultural affairs, and economic productivity (Dani, 2009). 


\section{International Conference on GlobalEducation $V$ "Global Education, Common Wealth, and Cultural Diversity"}

Scientific literacy has three dimensions. First, scientific concepts, which are needed to understand certain phenomena of the natural world and the changes made to it through human activity. Second, scientific processes, which are centered on the ability to acquire, interpret and act upon evidence. Third, scientific contexts or situations, selected mainly from people's everyday lives rather than from the practice of science in a school classroom or laboratory (Holbrook, 2009). In another perspective, scientific literacy was the major domain. The areas of application are: health, natural resources, the environment, hazards and the frontiers of science and technology. These are the areas in which scientific literacy has particular value for individuals and communities in enhancing and sustaining quality of life (Thomson, 2013).

In the daily life of students are often seen with the phenomena and the problems of science. They have a good scientific literacy are able to understand and to implement the scientific phenomenon well. Based on this reason, the science teaching in classroom should be able to promote and to develop scientific literacy of students well.

Integrated science teaching is considered be able to develop of scientific literacy of students. As the reason is facts and phenomena found in daily life generally in unity form. Nature usually shows itself as an unity and not separately. For example, water is a part of nature that can not be seen simply in terms of physics, chemistry, or biology, but it is an unity of water including its content and its characteristics. Another example is the air in nature may be viewed from various disciplines of science include physics, biology and chemistry.

In Indonesia country, the implementation of science teaching in junior high school should be integrated form. This reason is emphasized in policy of 2013 curriculum. In content approach of 2013 curriculum, students competence in junior high school are developed through an integrated and thematic of subject. On the other hand in the teaching process element, science is taught in an integrated teaching. Teaching content in junior high school is based on integrated concepts from different disciplines for education purpose of science subject. These integrated concepts are shown in core competence and basic competence. In a basic competence has integrated science concepts from sub discipline of biology, physics, chemistry, and earth and space science. Integrated science teaching is intended so that activities and experience to be received by students in teaching process is not much different from their everyday life. 
Therefore, teachers of science subject in junior high school needs to be implemented the integrated teaching well in the classroom.

In integrated science teaching, teacher integrates among the sub disciplines of science subject including biology, physics and chemistry. When teachers integrate the sub disciplines within a subject area, they are using an intra disciplinary approach. Integrated science integrates the perspectives of sub disciplines such as biology, chemistry, physics, earth or space science (Drake, 2004). A slightly more interdisciplinary approach than the correlated curriculum is a shared curriculum, where a course is designed that focuses on broad, thematic, and integrated concepts. An example of such a course is a general science course that covers topics in biology, chemistry and physics simultaneously (Yarker, 2012). The implementation of integrated science, an interdisciplinary subject that intentionally applies methodology and language from more than one science disciplines such as biology, chemistry, physics, earth science, life science to address a scientific theme, topic, or problem. Integrated science education emphasizes fundamental unity of scientific knowledge and encourages students to combine perspectives, concepts and methods from various disciplines to comprehend and interpret scientific phenomena in daily life (Sun, 2013).

Implementation the integrated science gives some advantages for students. Integrating science into other disciplines brings about meaning to science, helps students understand the role science plays in society, and makes science more realistic (Yarker, 2012). Integration is a universal phenomenon prominent in science than other fields of studies for obvious reasons: in the first place, when applied to science teaching and learning, the word integrated means that the concept of the fundamental unity of science; the commonality of approach to problems of scientific nature' and are helped to gain an understanding of the role and functions of science in everyday life and the world in which they live (Afuwave, 2012).

Implementation of the integrated science will encourage the goal of science education in school. This is consistent with the framework of curriculum development of junior high school. The curriculum development is conducted to achieve dimension of knowledge competence, scientific work, and scientific attitude as everyday behavior in interacting with the community, the environment and the use of technology. Therefore, science teaching in junior high school should be has contexts. It is mean that teaching material is connected to everyday life activities, environment and technology. 


\section{International Conference on GlobalEducation $V$ "Global Education, Common Wealth, and Cultural Diversity"}

The implementation condition in school of integrated science teaching is not suitable with expected ideal condition. From preliminary research was found three facts of integrated science teaching. The first fact was found from interview with ten science teachers in West Sumatra. Instrument used was questionnaires sheet consisting of the teacher's views on the integrated science, the implementation of integrated science teaching, the problem in integrated science teaching, and the factors that cause problems. The results of the interview were: 1). all science teachers stated that integrated science teaching is important in science teaching, 2). in implementation of integrated science teaching is not effective yet, 3). problems in integrated science teaching was weakness of understanding and example of comprehensive science teaching material is not available, and 4). factors that cause problems were educational background, difficulty of obtaining integrated science material, and facilities to support integrated science teaching. These results indicate that teachers have some difficulty in implementing the integrated science teaching in the classroom.

Second fact was found from analysis of integrated science textbooks used by students to support the teaching process. Analysis used the assessment sheet of document for every chapter of integrated science textbook for junior high school grade VIII. Analysis result of ten science textbooks showed that percentage teaching material of biology, physics and chemistry separately respectively $40.0 \%, 35.6 \%$ and $21.1 \%$. Percentage of biology and physics material more than chemistry in integrated science textbooks. Percentage of integrated science is only 3.3\% and this integration found in textbook of 2013 curriculum. This result indicate that integrated teaching material of science is very low.

The third fact is the result of scientific literacy of Indonesia students. From PISA report in 2010 is known that the scientific literacy of students in Indonesia have not been satisfactory. Score of science literacy of Indonesian students was 382. Indonesia students ranking was 64 from 65 participating countries. Result of PISA report has shows that science literacy level of Indonesian students was very low (Gurria, 2014).

Problem of integrated science teaching is found from the deviation between the ideal conditions and the real conditions. For this reason, effort to solve this problem needs to be done. As an alternative solution to solve this problem is to develop an integrated science teaching material by integrating scientific literacy. The development of this teaching material is very important to support the implementation of integrated 
science teaching in schools. Theme of our digestive system healthy is an interesting theme to be investigated because it relates to food which is consumed and food process in the human body. In everyday life the students are involved with this theme.

The general objective of this research is to create the valid, practice, and effective integrated teaching material by integrating scientific literacy. While the specific objectives of the study are: 1). to determine the validity of the integrated science teaching material by integrating scientific literacy on our digestive system healthy theme and 2). to determine the practicality of the implementation of integrated science teaching material by integrating scientific literacy in scientific approach, and 3). to determine the effectiveness of implementation of integrated science teaching material on our digestive system healthy theme in scientific approach to improve students competence in junior high school grade VIII.

\section{RESEARCH METHOD}

Type of this research is research and development (R\&D). R\&D is a research method that is used to produce a specific product and to test the effectiveness of that product. Another definition of $\mathrm{R} \& \mathrm{D}$ is a process or steps to develop a new product or improve existing products that can be justified. In educational research, product of R\&D including teaching model, teaching approach, teaching material, teaching media, teaching software, and so on.

In development of integrated science teaching material, there are seven steps of activity. Steps $R \& D$ are to understand the potential and problem, to collect the information, to design the product, to validate the product, to revise the product, to do the limited field testing, and to revise the product. From the results of preliminary research on first step and second step was designed the integrated science teaching material. This teaching material was validated by five experts from of physics, biology and chemistry education. Limited field testing was conducted to determine the practicality and effectiveness the implementation of integrated science teaching material in scientific approach.

Research design in limited field testing was before and after treatment. Pretest was given to students before implementing the integrated science teaching material to determine student's competence on initial condition. Scientific approach using integrated science teaching material by integrating in scientific approach was conducted 


\section{International Conference on GlobalEducation $V$ "GlobalEducation, Common Wealth, and Cultural Diversity"}

for four meetings. After that, posttest was given to students to determine competence of students on final condition.

To get the data in research activity was used four research instruments. First, achievement test sheet to determine the cognitive competence of students before and after implementing integrated science teaching material by integrating scientific literacy in scientific approach. Second, questionnaire sheet to determine the practicality of the implementation of integrated science teaching material by integrating scientific literacy of teachers and students. Third, skill assessment sheet of students in scientific literacy skill form. Assessment of performance includes the ability to create mind mapping, to conduct investigation, to report the results of investigation, to present the result of investigation, and to make task of applying science in daily life. Finally, observation sheet to assess the attitudes of students in teaching process.

In research activities, there were four types of data analysis techniques namely descriptive statistical analysis, graph method, correlation analysis, and correlation compare mean test. Descriptive analysis was used to determine more detailed information from the data knowledge competence, skill competence skills in scientific literacy form. Descriptive statistics parameters of these competencies including: average value, median, mode, standard deviation, variance, and so on. Graph method was used to give a visual impression of validity and practicality of integrated science teaching material by integrating scientific literacy. Correlation analysis was used to determine the value of regression coefficient between knowledge competence after and before treatment. Besides that, this analysis was also used to determine correlation coefficient value for scientific literacy and attitude competence of students. On the other hand correlation compare mean test was used to determine the effectiveness on implementation of integrated science teaching material in the scientific approach.

\section{RESULT AND DISCUSSION}

In validity test of integrated science teaching material was obtained from assessment result of experts based on their rational thinking. In limited field testing activity was obtained assessment data of teachers and students about practicality the implementation of integrated science teaching material. In addition, in limited field testing was also obtained data of scientific literacy and attitudes of students in 
implementing the integrated science teaching material in scientific approach. From these data, there are three results of this research.

First research result is validity level of integrated science teaching material by scientific literacy. Assessment of integrated science teaching materials consist of six components, namely: 1). feasibility component of teaching material content, 2). feasibility component of representation, 3). integration component of teaching material, 4). use component of language, 5). graph component in teaching material, and 6). and integration component of scientific literacy in teaching material. The average value of validation result for every component of assessment can be seen in Figure 1

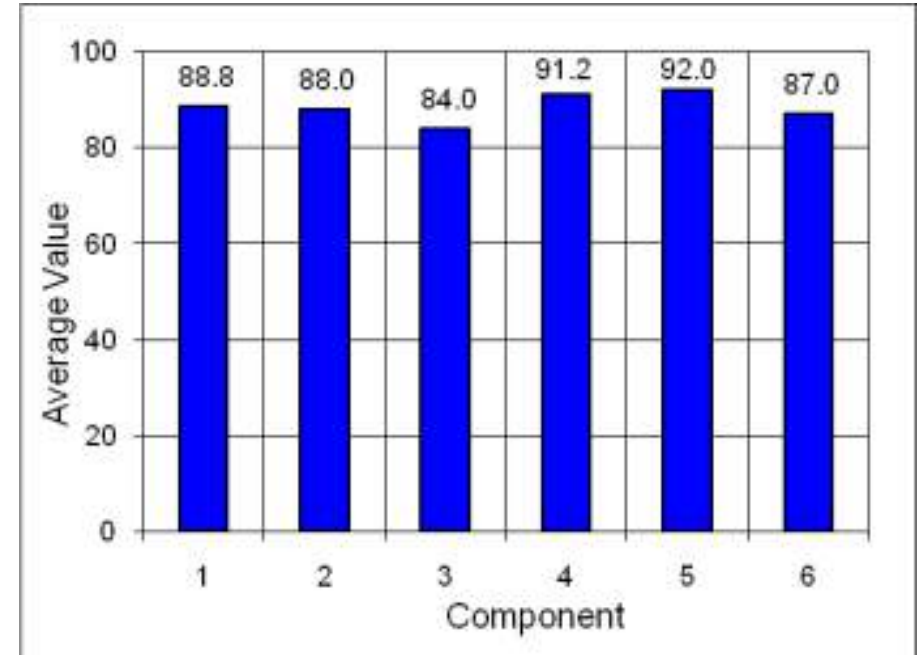

Figure 1. Validity Value of Every Component

From Figure 1 it can be stated that the validity range of every component of assessment from 84.0 to 92.0 . The lowest value is integration component of teaching material of science and the highest value is graphic component in teaching material. The average value of validity of six components is 88.5. This average value can be categorized into very valid.

From validity test activity of integrated science teaching materials was found weakness. This weakness was known from the suggestion of experts. There were some suggestion from experts, namely: indicators of basic competence needs to be refined, integration level in teaching material was still low, tidiness and consistency in teaching material need to be considered, and figure in teaching material was made more interesting. Improvement on integrated science teaching material was based on suggestion of experts. 


\section{International Conference on Glo6alEducation $\mathcal{V}$ "GlobalEducation, Common Wealth, and Cultural Diversity"}

The second result of this research is practicality of implementation of integrated science teaching material by integrating scientific literacy. Practicality of implementation of teaching material was obtained from teachers as practitioner in school and students as users of teaching material. Practicality instrument the implementation of teaching material for teachers prepared on four components namely: 1). content component of teaching material, 2). representation component in teaching material, 3). easiness component of implementation, and 4). advantages of teaching material for teachers. Practicality value of implementation of integrated science teaching material by integrating scientific literacy according in each component is shown in Figure 2

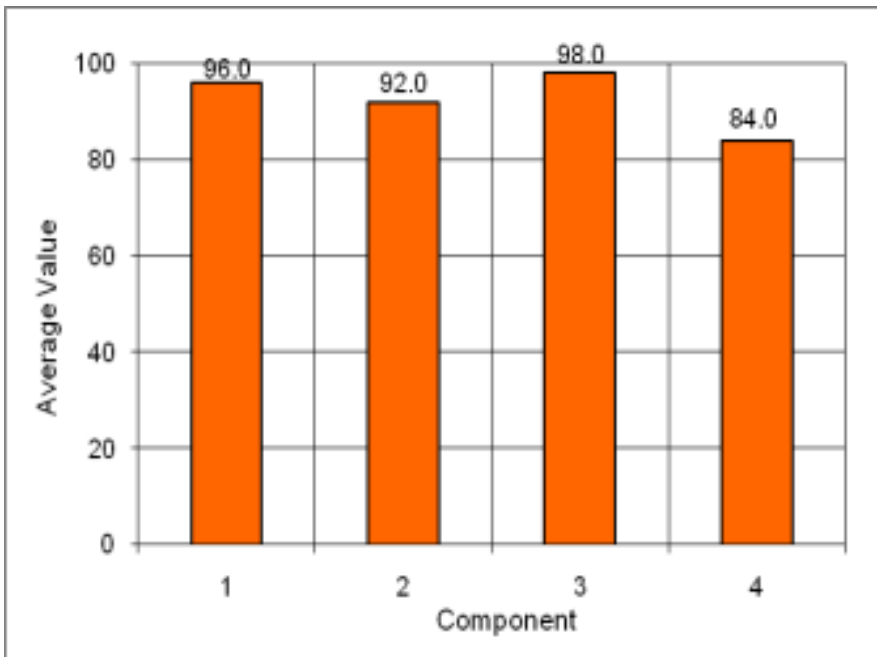

Figure 2. Value of Practicality According Teachers

Based on Figure 2 it can be explained that range value of practicality component of the implementation of integrated science teaching material by integrating scientific literacy from 84.0 to 98 . The lowest practicality value on advantages perceived by teachers while highest value is the easiness and used up of teaching material in teaching process. The practicality average value of the implementation of integrated science teaching material according teachers is 92.5 . This average value can be incorporated into very practice.

At last meeting of teaching, students were given questionnaire to determine practicality of the implementation of integrated science teaching material by integrating scientific literacy. Components of questionnaire instrument consists of five parts, namely: 1). easiness in learning, 2). unity of material in teaching material 3). motivation in learning, 4). supporting to understand the teaching material, and 5). used up teaching 
material in learning. Practicality value of the implementation of integrated science teaching material by students listed in Figure 3.

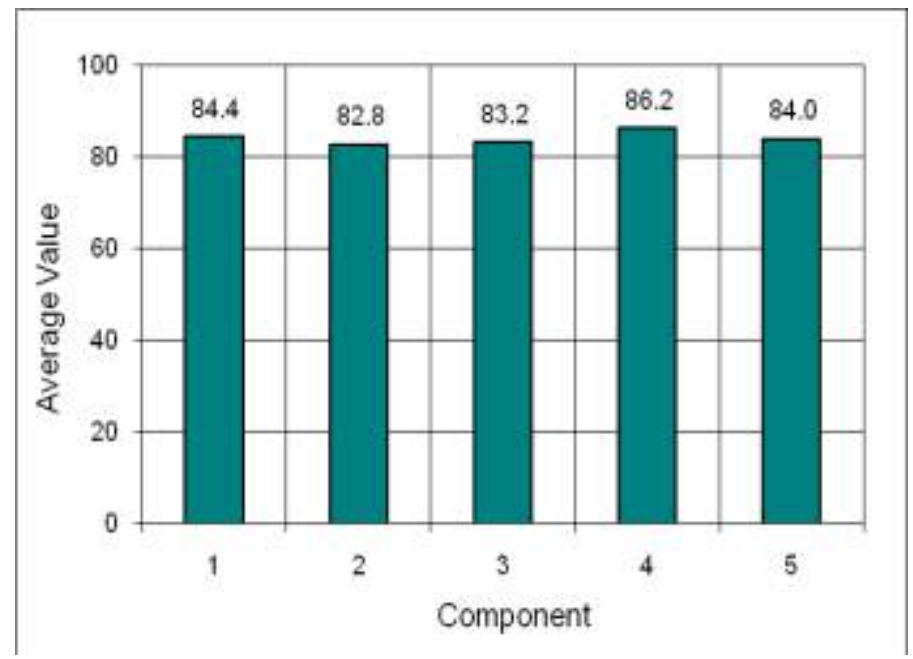

Figure 3. Practicality Value According Students

In Figure 3 it can be expressed that the range practicality component value of the implementation of integrated science teaching material by integrating scientific literacy from 82.8 to 86.2 . The lowest practicality value is material unity component in teaching material, while the highest practicality value is on supporting of teaching material in improving students understanding of teaching material. The average value of practicality the implementation this integrated science teaching material by students is 84.1. This is mean that average value of practicality of the implementation of integrated science teaching material is very practice according the students.

The third result of this research is effectiveness of the implementation of integrated science teaching material by integrating scientific literacy in scientific approach. The effectiveness in implementation of integrated science teaching material can be determined from comparison between knowledge competence of students before and after implementation of integrated science teaching material. Data of competence before and after obtained from the value of pretest and posttest. The average value of pretest and standard deviation of 30 students respectively 68.8 and 7.0. Meanwhile, average value of posttest and standard deviation of students respectively 90.8 and 5.5. Value of correlation coefficient between posttest and pretest is 0.3 . Correlation coefficient value between pretest posttest result can be included into low category.

Calculate value of correlation compare mean test for knowledge competency is determined from average value, standard deviation, and correlation coefficient. From the calculation result obtained value $t_{c}=-16.6$. For number of students 32 people is 


\section{International Conference on GlobalEducation $V$ "Global Education, Common Wealth, and Cultural Diversity"}

obtained freedom degree is 31 . The table value of $\mathrm{t}$ for 31 freedom degree and level confidence of $95 \%$ is 1.7 . By using left area of one-tailed test obtained t value is smaller than $t$ table. This is mean base on $t$ test can be stated that there are significant difference the knowledge competence of students between after and before they use integrated science teaching material by integrating scientific literacy. Thus, the implementation of integrated science teaching material by integrating scientific literacy in scientific approach is effective to improve the knowledge competence of students.

Effectiveness of the implementation of integrated science teaching material on skill competency is determined from the data of scientific literacy. In this research, the data of scientific literacy consist of scientific concepts, scientific processes and scientific contexts. The data of scientific concepts is determined from the ability of students to create mind maps. Data of scientific processes is taken from investigation performance assessment, report of investigation result and presentation of investigation result. On the other hand, data of scientific contexts is taken from assessment of application task of relevant learning material in daily life.

Value of $t$ is determined from performance assessment data before and during implementation of integrated science teaching material by integrating scientific literacy. Value of $t$ for the ability of students create mind map is -20.23 . Value of $t$ for the ability of students to do investigation, to make report of investigation result, and to present of investigation result respectively $-27.64,-19.4$ and -20.58 . All the $t$ values are smaller than $\mathrm{t}$ table on the left are of one-tailed test. From this analysis result, it can be stated that there is significant difference between skill competence of student in scientific concepts, scientific processes and scientific contexts after and before they use integrated science teaching material. This is mean the implementation of integrated science teaching material by integrating scientific literacy is effective to improve scientific concepts, scientific processes and scientific contexts. Therefore, the implementation of integrated science teaching material by integrating scientific literacy is effective to improve the scientific literacy of students.

Effectiveness the implementation of integrated science teaching material by integrating scientific literacy on attitudes competency is determined from attitudes observation assessment of students in the learning process. In learning process the attitudes of students is nurturant effects of scientific activities in teaching. Value of $t$ is obtained from the average value, standard deviation, variance, and number of students. 
Value of $t$ for attitudes competence of students is -23.67 . This attitudes value is smaller than value $t$ table on the left area of one-tailed test. This result indicate that there is significant difference between after attitude competence of student and before they use integrated science teaching material by integrating scientific literacy. Therefore, the implementation of integrated science teaching materials by integrating scientific literacy is effective to improve the attitudes competence of students.

Based on the result of this research it can be stated that the product of integrated science teaching material by integrating scientific literacy for our digestive system health theme has a high validity value. This is happen because the arrangement of teaching material based on basic competence. From the basic competence is derived indicators to achieve basic competencies and learning objectives. The formulation of theme has been based on contexts that related to everyday life of students. Assessment experts are based on criteria of good teaching material including feasibility of content, use of language, representation in teaching material, and graphic of teaching material. Validity test of integrated science teaching material has been based on certain criteria. The intervention should address a need, and its components should be based on state-of the-art knowledge (content validity, also called relevance) and all components should be consistently linked to each other (construct validity, also called consistency). If the intervention meets these requirements, it is considered to be valid (Akker, 2013).

The implementation of integrated science teaching material by integrating scientific literacy is practice and effective in scientific approach. Teachers and students stated that the implementation of this teaching material is practice in teaching process. It is mean that teachers and students feel easiness, used up, and advantages of integrated science teaching material in learning process. In addition, the implementation of this integrated science teaching material can improve the knowledge competency, skill competence in scientific literacy form and attitudes competence of students. Second characteristic of high-quality interventions is that teachers consider the intervention to be usable and that it is easy for them to use the intervention in a way that is largely compatible with the developers' intentions. $f$ these conditions are met, we call these interventions practical. A third characteristic of high quality interventions is that they result in the desired outcomes, i.e. that the intervention is effective (Akker, 2013).

In implementation of this research was found four limitations. First, teaching material developed in integrated science teaching material only consist of two main 


\section{International Conference on GlobalEducation $V$ "GlobalEducation, Common Wealth, and Cultural Diversity"}

materials namely additives substances and addictives substances associated with food and human digestive system. Second, integrating model used in this integrated science teaching material is webbed model. Third, literacy of students which is integrated into teaching material is scientific literacy. Finally, field testing on development stage is limited field testing for one class of students grade VIII. For this reason, the follow-up of this research need to be done.

\section{CONCLUSION}

Research results were found from data analysis of validity, practicality, and effectiveness test in implementing of integrated science teaching material. From the data analysis can be stated three conclusions as result of this research.

1. The average value of validity of content feasibility component of teaching material, feasibility of representation in teaching material, integration of sub disciplines material of science in teaching material, use of language in teaching material, graphic in teaching material, and integration of literacy scientific in teaching material is 88.5. The validity average value of integrated science teaching material by integrating literacy can be categorized into very valid.

2. The implementation of integrated science teaching material by integrating scientific literacy is very practice in scientific approach according teachers and students. The average value of the effectiveness of the implementation of integrated science teaching material according teachers and students respectively 92.5 and 84.1

3. The implementation of integrated science teaching material by integrating scientific literacy is effective to improve knowledge competence, skill competencies and attitudes competence of students. Skill competence is indicated by performance of students in scientific literacy form including scientific concepts, scientific processes and scientific contexts.

\section{REFERENCES}

Afuwave. 2012. Integration in Science Teaching - Learning: Problems and Prospects. Afrrev Stech, An International Journal of Science and Technology Bahir Dar, Vol.1 (3), 126-133

Akker, Jan van den. 2013. Education Research Design. Netherlands Institute for Curriculum Development (SLO), Enschede, the Netherlands

Akgul, Esra Macaroglu. 2004. Teaching Scientific Literacy Through A Science Technology and Society Course: Prospective Elementary Science Teacher's 
Case. The Turkish Online Journal of Educational Technology, TOJET, ISSN: 1303-6521 volume 3 Issue 4

Carroll, Crystal Jayne, (2013). The Effects of Parental Literacy Involvement and Child Reading Interest on the Development of Emergent Literacy Skills. Theses and Dissertations. University of Wisconsin-Milwaukee

Dani, Danielle. 2009. Scientific Literacy and Purposes for Teaching Science: A Case Study of Lebanese Private School Teachers International Journal of Environmental \& Science Education, Vol. 4, No. 3, 289-299

Drake, Susan M and Burns, Rebecca C. 2004. Meeting Standards Through Integrated Curriculum. Association for Supervision and Development Alexandria, Virginia USA

Gurria, Angel. 2014. PISA 2012 Results in Focus: What 15-Year-Olds Know and What They can Do with What They Know. Programme for International Students Assessment, OECD.

Jack Holbrook, Jack. 2009. The Meaning of Scientific Literacy. International Journal of Environmental \& Science Education Vol. 4, No. 3, 275-288

Kiyici, Fatime Balkan. (2007). Special Issue on Scientific Literacy. The Turkish Online Journal of Educational Technology, TOJET ISSN: 1303-6521 volume 6 Issue 2

National Science Teachers Association (NTSA). 2003. Standards for Science Teacher Preparation. Department of Teaching, Learning and Teacher Education, University of Nebraska - Lincoln

Nichols, Jennifer Rita. 2015. 4 Essential Rules Of 21st Century Learning. Teachthought We Grow Teacher

Ogunkola, Babalola J. 2013. Scientific Literacy: Conceptual Overview, Importance and Strategies for Improvement. Journal of Educational and Social Research. Vol 3 (1)

Robinson, Mike and Crowther, David. 2001. Environmental Science Literacy in Science Education, Biology \& Chemistry Majors. The American Biology Teacher, Volume 63, No. 1

Ronis, Diani. 2001. Problem-Based Learning for Math and Science: Integrating Inquiry and the Internet. A Pearson Education Company, Skylight Training and Publishing, Inc.

Sun, Daner. 2014. Status of Integrated Science Instruction in Junior Secondary Schools in China: An Exploratory Study. International Journal of Science Education, 36(5), 808-838

Thomson, Sue. 2013. A Teacher's Guide to PISA Scientific Literacy. Programme for International Student Assessment, Australian Council for Educational Research Ltd

Yarker, Morgan B and Park, Soonhye. 2012. Analysis of Teaching Resources for Implementing an Interdisciplinary Approach in the K-12 Classroom. Eurasia Journal of Mathematics, Science \& Technology Education : 223-232. 